\title{
Results of a Preliminary Assessment of an Explosive Projectile Launch System
}

\author{
John E. Reaugh
}

July 31,1995

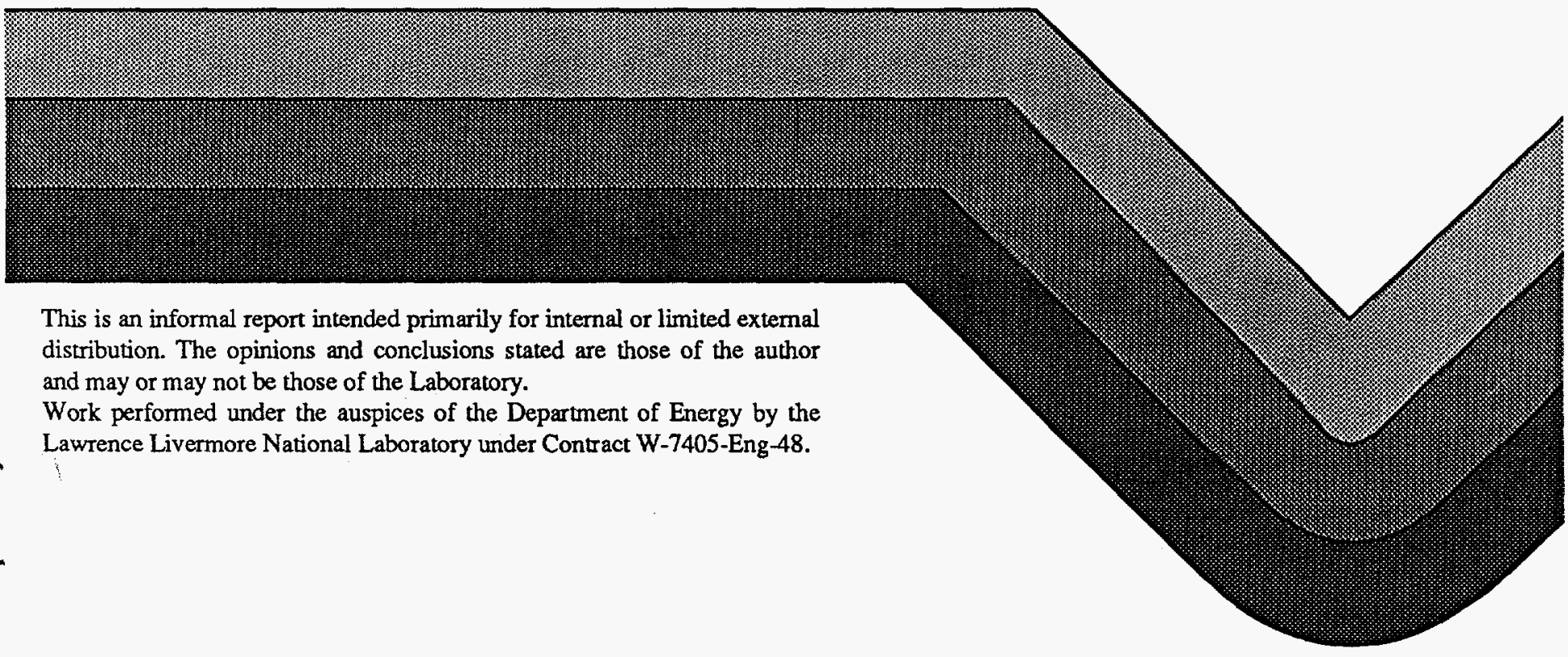

This is an informal report intended primarily for internal or limited external distribution. The opinions and conclusions stated are those of the author and may or may not be those of the Laboratory.

Work performed under the auspices of the Department of Energy by the Lawrence Livermore National Laboratory under Contract W-7405-Eng-48. 


\section{DISCLAIMER}

This report was prepared as an account of work sponsored. by an agency of the United States Government. Neither the United States Government nor any agency thereof, nor any of their employees, make any warranty, express or implied, or assumes any legal liability or responsibility for the accuracy, completeness, or usefulness of any information, apparatus, product, or process disclosed, or represents that its use would not infringe privately owned rights. Reference herein to any specific commercial product, process, or service by trade name, trademark, manufacturer, or otherwise does not necessarily constitute or imply its endorsement, recommendation, or favoring by the United States Government or any agency thereof. The views and opinions of authors expressed herein do not necessarily state or reflect those of the United States Government or any agency thereof. 


\section{DISCLAIMER}

Portions of this document may be illegible in electronic image products. Images are produced from the best available original document. 


\title{
Results of a preliminary assessment of an explosive projectile launch system
}

\author{
John E. Reaugh \\ H-Division \\ Physics and Space Technology Directorate \\ Lawrence Livermore National Laboratory \\ July 31,1995
}

\section{BACKGROUND}

Dennis Wilson, Hans Mark, and Philip Varghese from IAT, Austin, TX, presented to LLNL an idea to accelerate projectiles by a sequence of timed explosions. We performed computer simulations with CALE, a two-dimensional Arbitrary Lagrange Eulerian program, to examine the operating principles and preferred operating parameters of such a device. Our examination was brief, so we fixed some of the parameters that would be optimized in a design study.

\section{CONCLUSIONS}

We have identified an explosive charge size and relative projectile position that keeps the pressure acting on the projectile less than $10 \mathrm{kbar}(1 \mathrm{GPa})$. That explosive amount is insufficient to produce a large velocity change, so that 40 stages would be needed to achieve $3 \mathrm{~km} / \mathrm{s}$. When we increased the charge substantially, we could increase the velocity of a given stage substantially (only 4 stages needed to reach $3 \mathrm{~km} / \mathrm{s}$ ), but at the expense of projectile and barrel distortion. We have identified areas of research needed to quantify the velocity increment per stage that can be achieved without projectile or barrel distortion.

\section{SCOPE}

The principle of operation of Wilson's acceleration scheme is that the blast wave from an explosion stagnates on the aft side of the projectile and accelerates it by the overpressure impulse of the reflected shock. A sequence of stages would be used to accelerate the projectile. For definiteness, we specified the gun caliber and projectile weight, choosing a $25 \mathrm{~mm}$ cannon with a $130 \mathrm{~g}$ projectile. This is a convenient size for an experimental program. In addition, the caliber and the projectile weight are those used for the APFSDS (armor-piercing fin-stabilized discarding-sabot) long-rod projectile shot from the Bushmaster cannon, which is the main armament of the Bradley Fighting Vehicle. We show the geometry of a $130 \mathrm{~g}$ full-caliber projectile in Fig 1.

We chose the projectile to have the properties of 4340 steel at Rockwell hardness Rc35. (The Brinell hardness is $330 \mathrm{~kg} / \mathrm{sq}$. mm, and yield strength is $10 \mathrm{kbar}=1 \mathrm{GPa}$.) Although this steel can be hardened to considerably higher strength, that state is accom- 
panied by significantly reduced ductility. We have assumed that since the projectile would experience multiple explosions, it should not flow plastically from a single explosion. In our preliminary studies of acceleration, we have ignored details of implementation. Instead of including barrel response, we modeled the barrel wall as an unmoving boundary, and magically placed the explosive aft of the projectile in a half-ring at the barrel circumference (See Fig 1) We used the explosive properties of Detasheet, which is a PETN-based commercial product that detonates reliably in small sizes, is convenient to use, and has a sufficiently high explosive output. We used a non-ideal air equation of state that was developed for describing strong shocks.

\section{RESULTS FOR $1 \mathrm{~g}$ of EXPLOSIVE}

We used 1 gram of explosive in a ring with semicircular cross-section, as shown in Fig 1. With the projectile in the position shown, we recorded the pressure history with Lagrange tracer points, which follow the local material motion, that were originally located at $2 \mathrm{~mm}$ radial intervals near the tail of the projectile. They are shown as locations A through $\mathrm{F}$ in Fig 1. The output from these (computational) gauges records the initial blast wave and the reflected waves from the projectile as well. We show the pressure histories in Fig 2. At the projectile position selected, the peak pressure never exceeds 10 $\mathrm{kbar}$, the nominal strength of the projectile. We felt that this would result in purely elastic deformation of the projectile. Except for a few zones near the pointed tail of the projectile, this was the case. The plastic strain in those near-axis zones may be a numerical rather than a physical result.

Examination of Fig 2 shows significantly more structure than a simple reflected shock. Tracer B is closest to the center of the explosive and shows the earliest arrival. Tracer A, although slightly farther away, has higher pressure because of the cylindrical convergence toward the barrel axis of symmetry. The wave at $C$ arrives later because $C$ is farther away than $\mathrm{A}$, and because the pressure at $\mathrm{C}$ is lower, with a consequent slower shock speed. The "corner" near tracer point $\mathrm{F}$ is the location where the shoulder of the projectile meets the barrel wall. The reflected shock from that corner results in a higher pressure than the initial shock for tracers $\mathrm{E}$, and $\mathrm{F}$.

We integrated the individual pressure histories over space to get the force acting on the projectile. The force history (Fig. 3) shows the significant influence of the corner reflection at about $10 \mu \mathrm{sec}$. We integrate the force history in time to get the momentum change of the projectile, and divide by the projectile mass $(130 \mathrm{~g})$ to get the increment in projectile velocity. (See Fig. 4.) The small velocity increment $(0.07 \mathrm{~km} / \mathrm{s})$ means that many stages would be needed to achieve substantial muzzle velocity. About 40 stages would be needed to reach $3 \mathrm{~km} / \mathrm{s}$.

If the design is successful, most of the stages will operate on a moving projectile. In addition, the background gas near the projectile moves with the projectile speed. In typical interior ballistics simulations, there is a uniform velocity gradient. The velocity of the propellant gas is zero at the breech and matches the projectile velocity at the projectile base. We performed a simulation of the same projectile and explosive set-up as before, but with the background gas and projectile moving at $3 \mathrm{~km} / \mathrm{s}$. The shock wave moving upstream (toward the breech) is much larger than the one moving downstream (toward the muzzle). We plot the pressure near the barrel wall as a function of axial distance in 
Fig 5. We note that the downstream air shock is small, but is moving faster than the upstream shock in the laboratory frame. The lower-pressure air shock results in a much reduced velocity increment from the $1-\mathrm{g}$ charge, to only $0.01 \mathrm{~km} / \mathrm{s}$. As a consequence, to achieve the same velocity increment at each stage will require a different charge at each stage, with higher velocity stages needing to use larger charge weights.

We also examined the effect of propagating a shock wave into high-pressure, high-temperature gas. Both the explosive products and the multi-shocked air will be at high temperature. Efficient use of barrel length requires a subsequent stage to operate before the pressure in the products of the preceding stages reduces to zero. We simulated the background gas by using our air equation of state at density $0.2 \mathrm{~g} / \mathrm{cc}$ and energy density $0.1 \mathrm{MJ} / \mathrm{g}$. This results in a pressure of $1 \mathrm{kbar}$. If the specific heat were constant, the temperature would have been $1000 \mathrm{~K}$. We used this condition for the projectile and background gas moving at $3 \mathrm{~km} / \mathrm{s}$. For this case, the projectile velocity increment was $0.02 \mathrm{~km} / \mathrm{s}$. As a consequence, the design is further complicated by the dependence of explosive weight on both the projectile velocity and the state of the background gas.

\section{RESULTS FOR $8 \mathrm{~g}$ of EXPLOSIVE}

We chose a substantial increase in the explosive weight to demonstrate both the potential increase in velocity per stage, and the potential projectile deformation that results from an overdriven system. We show the pressure histories at the previous tracer locations in Fig 6. Although the results are qualitatively similar, the peak values are about 10 times the previous values. The peak force and the velocity increment also have the same multiplier. At fixed distance from the charge, then, the velocity increment is approximately linear (1.1 power) with the charge weight.

However, this charge weight produces substantial distortion in the projectile due to plastic strain. (See Fig. 7.) Although it is possible for a steel projectile to withstand some distortion without in-barrel or out-of-barrel failure, we think that a design based on multiple stages, each of which produces significant distortion, would be intrinsically risky. The change in shape from stage to stage would further complicate the design. In addition, the corner near tracer F (see Fig. 1) would show both barrel and projectile distortion. Permanent barrel distortion could be permitted in a one-shot system. Even with a one-shot system, however, permanent distortion for both projectile and barrel in the same vicinity could result in a projectile that no longer fits, which would prevent the device from working even once.

\section{SUMMARY}

We have performed a limited study using computer simulations to examine an idea for using explosives to accelerate a projectile in stages. A light explosive loading resulted in essentially no projectile deformation. The peak pressure on the barrel is larger than that typically used, but the duration of that peak pressure is less. Further study is required to address the issue of barrel response during the transient loading. By staying below the projectile yield stress, we saw no permanent deformation, and are reasonably confident that the projectile would survive. The velocity increment experienced by the projectile is small. As a consequence, many stages (about 40 ) would be needed to 
achieve $3 \mathrm{~km} / \mathrm{s}$. Increasing the explosive weight per stage increases the velocity increment per stage, and reduces the required number of stages, but with increasing likelihood of projectile and/or barrel failure. A complication to the engineering of a workable system is that each stage needs a separate analysis (or at least an interpolated analysis). The velocity increment from a given charge depends significantly on the projectile velocity and the background gas density.

There a number of issues that need addressing by a significant research program. A figure of merit for a given stage is the ratio of velocity increment to peak pressure. A high ratio is desirable. Research is needed to address the effect of projectile shape and proximity to the explosive on that figure of merit. Research is needed to address projectile heating by the stagnating air shock and/or penetration of that layer by explosive products. The heating, if substantial, would reduce the maximum permitted pressure because of reduced projectile strength. Research is needed to address the projectile and barrel interaction. Research is needed to address the containment of explosive products so as to avoid distortion near the explosive emplacement that would require either repair or replacement of parts after each firing. Research is needed to address the changes to the programmed detonation sequence that different bullet weights and configurations would require. 


\section{FIGURE CAPTIONS}

Fig 1. Cross section of the $25 \mathrm{~mm}$ projectile and ring of explosive used in the simulations. Labels A-F show the original location of the Lagrange tracer points.

Fig 2. Pressure history recorded at the six tracer points from the calculation using $1 \mathrm{~g}$ of Detasheet.

Fig 3. Force history acting on the projectile tail. This curve is obtained by a spatial integration of the six pressure histories shown in Fig 2.

Fig 4. Velocity increase of a $130 \mathrm{~g}$ projectile subject to the force history shown in Fig 3.

Fig 5. Axial profile of the pressure in air and in the explosive products taken at the outer radius of the cannon. Curve 1 at 2 microsec from explosive initiation, Curve 0 at 3 microsec, and Curve 2 at 4 microsec. The background gas velocity is $3 \mathrm{~km} / \mathrm{s}$ from left to right. Distance is in $\mathrm{cm}$. Full scale pressure is $0.5 \mathrm{kbar}(50 \mathrm{MPa})$.

Fig 6. Pressure history recorded at the six tracer points from the calculation using $8 \mathrm{~g}$ of Detasheet.

Fig 7. Cross section of the projectile subject to an $8 \mathrm{~g}$ charge. The horizontal lines are the immobile barrel wall. The irregular curves aft of the projectile show the irregular interface between the explosive products and air. Some of the projectile distortion is caused by the direct shock near the axis. The distortion near the outer boundary of the projectile is caused by the $40 \mathrm{kbar}(4 \mathrm{GPa}$ ) shock reflected from the intersection of the projectile base and the barrel wall. The degree of shading corresponds to the equivalent plastic strain between 0 and 0.75 . Although some of the elevated plastic strain at the surface may be numerical, the peak plastic strain on the axis in the projectile interior exceeds 0.15 , and exceeds 0.2 in a substantial volume of the projectile. 
$i^{5}$

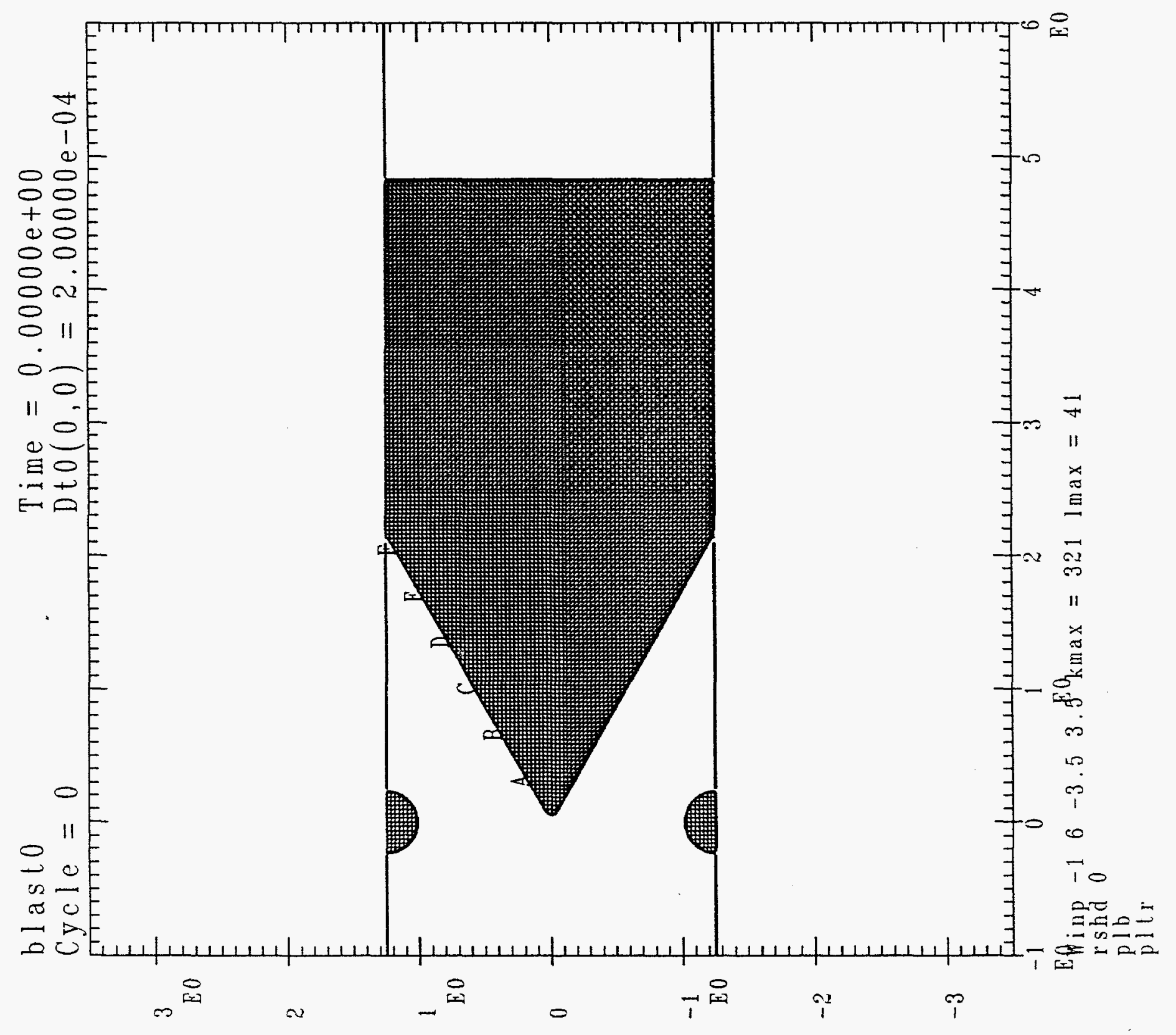

Fig 
$N$
4

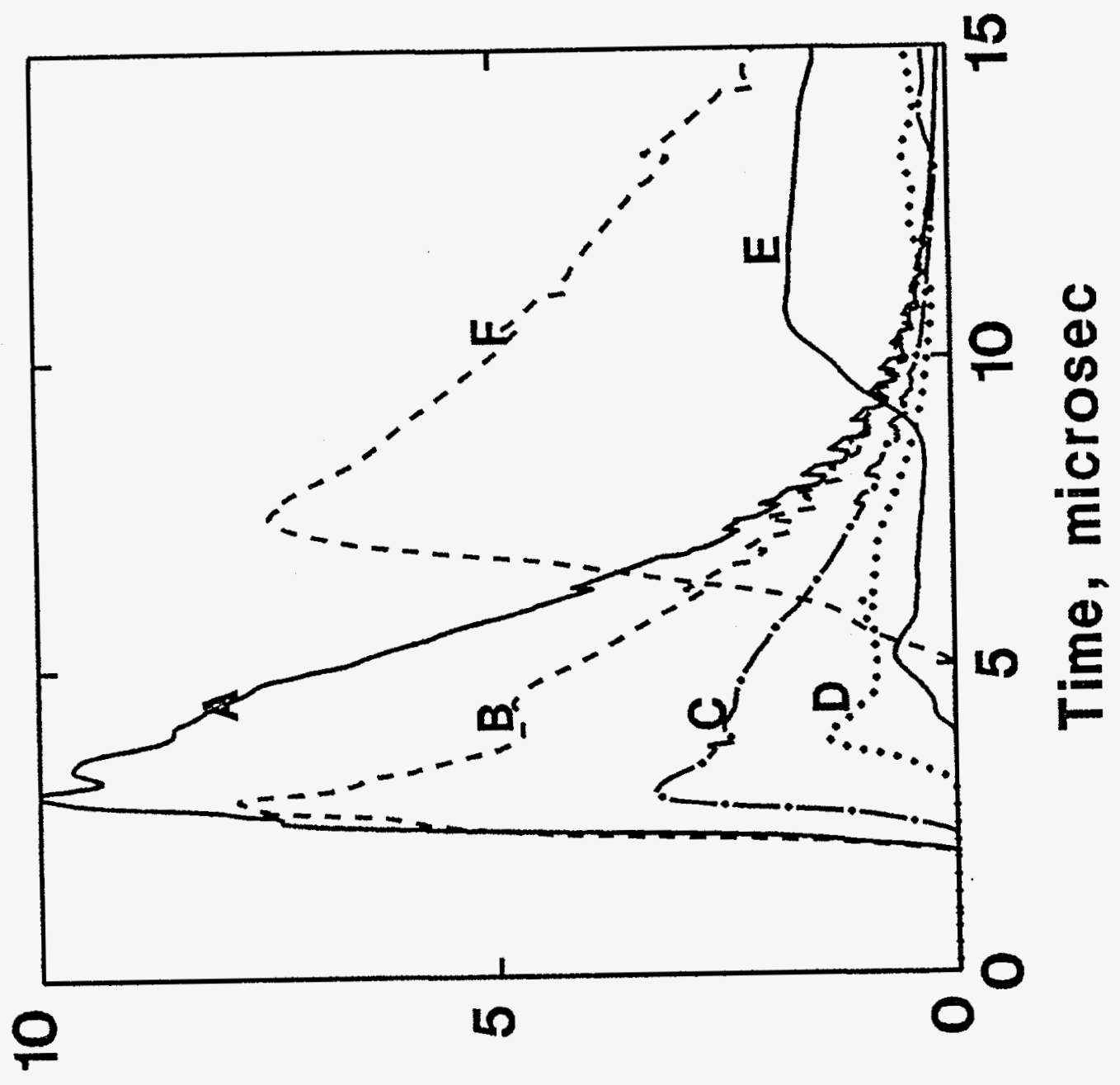

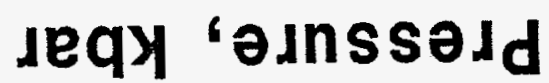


品

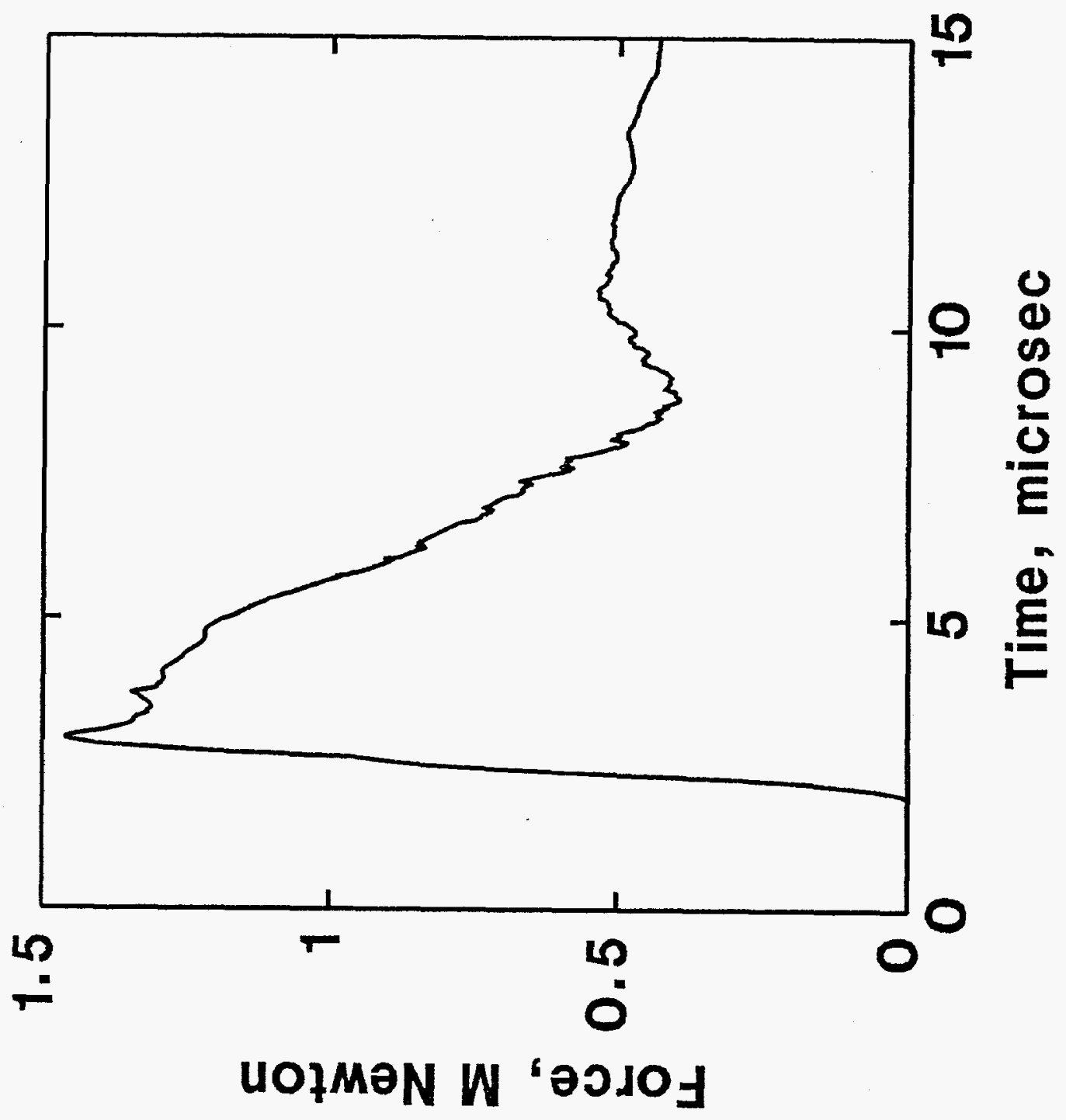


or

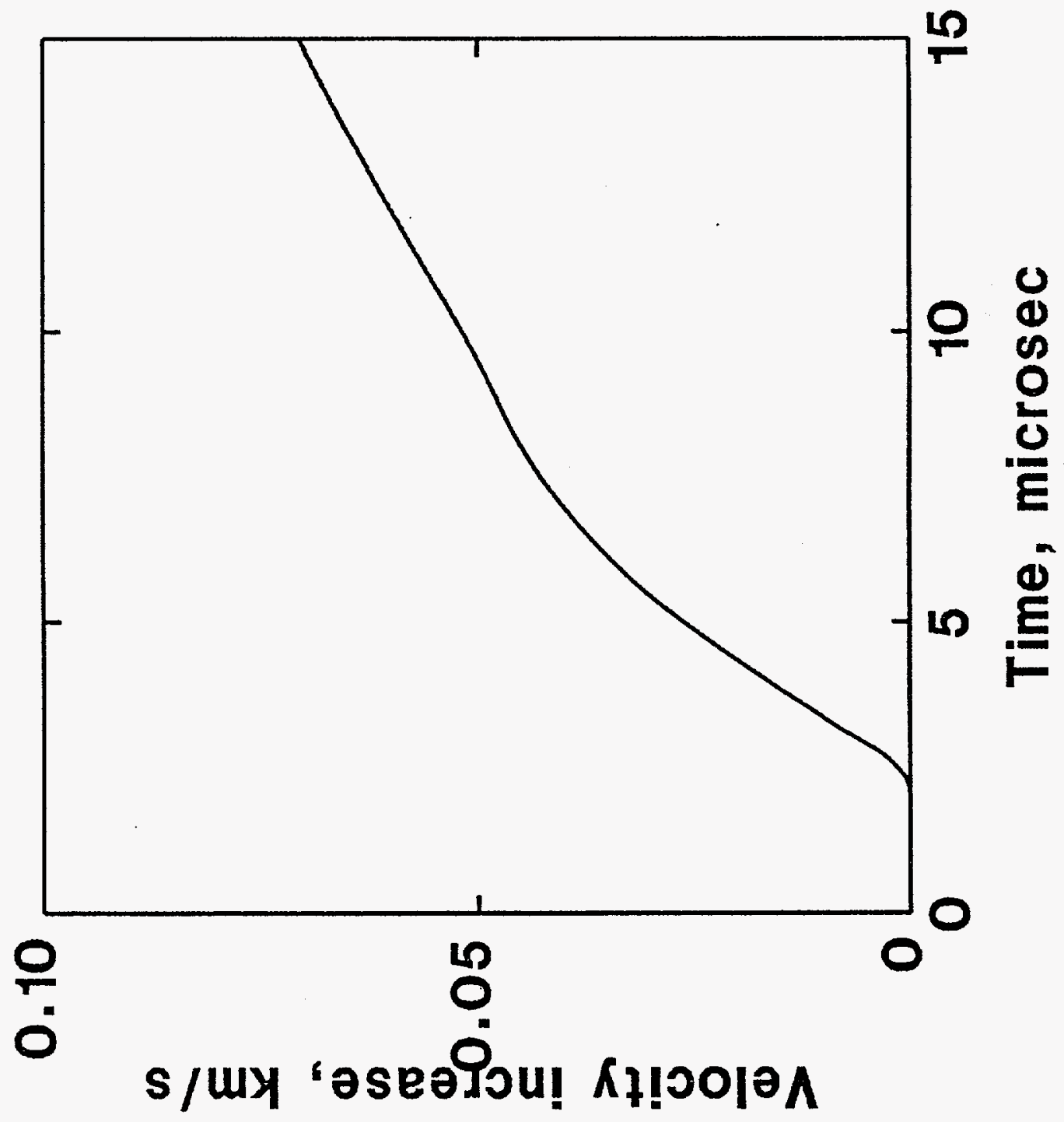




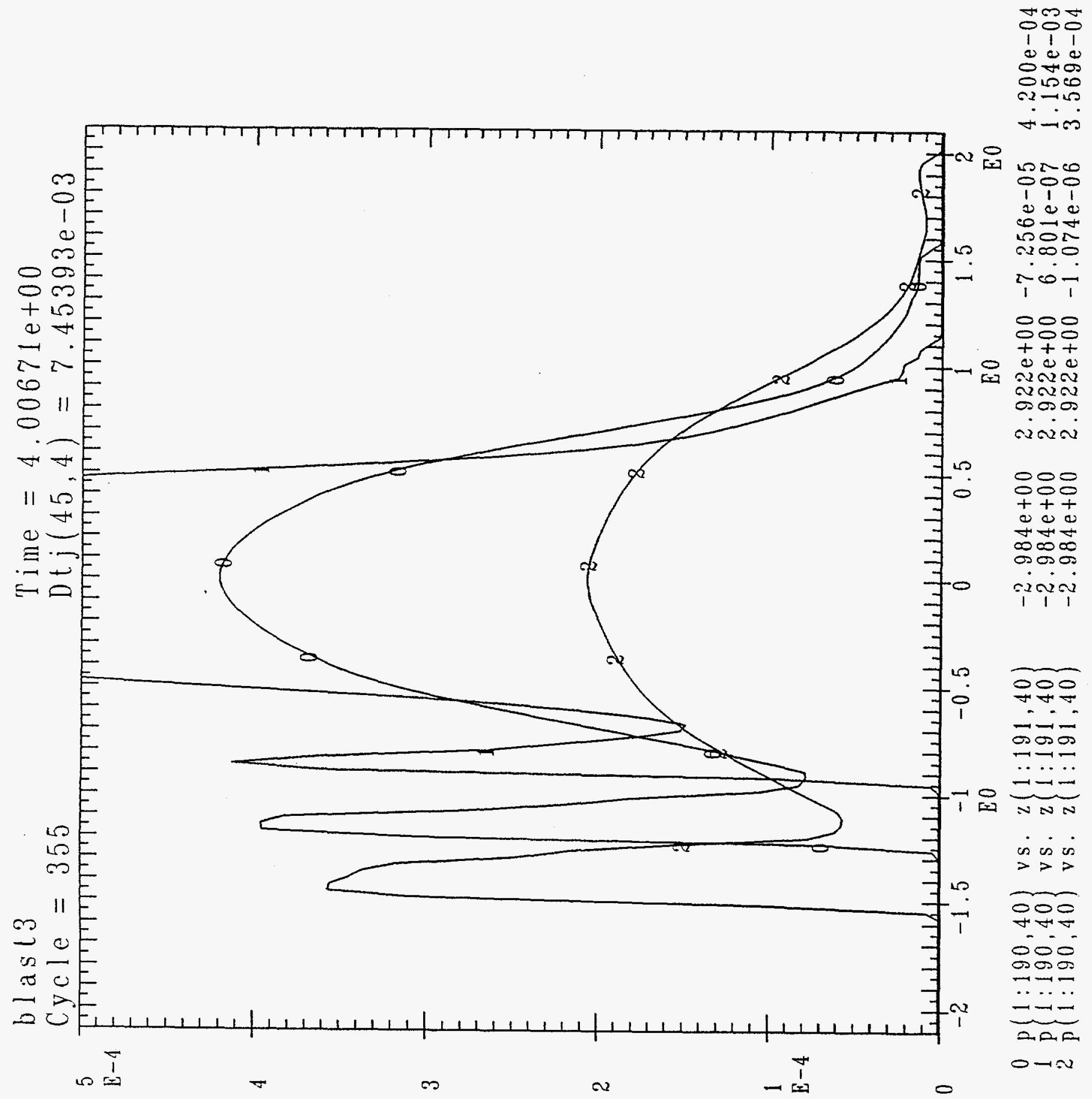




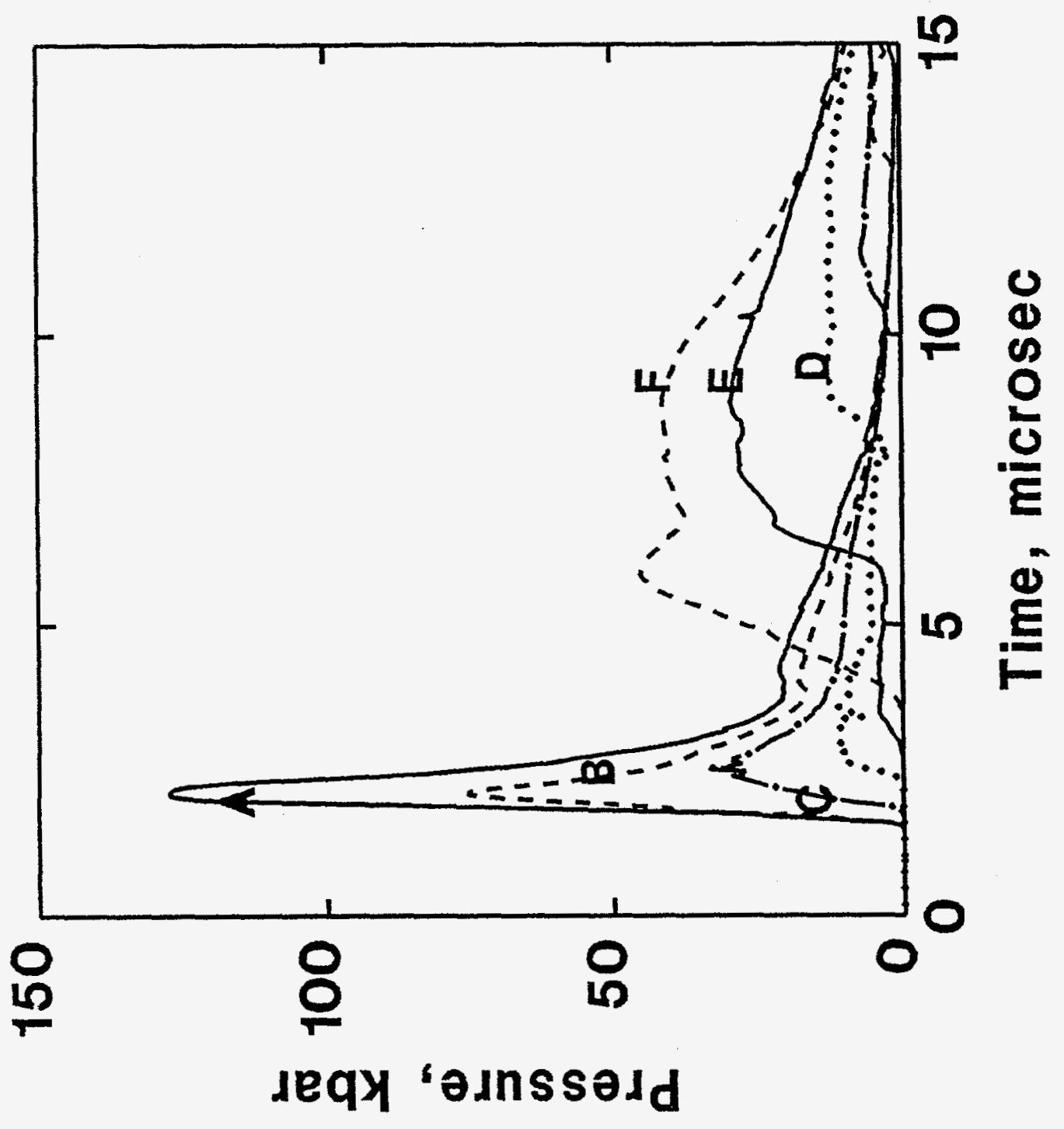

Fig 6 

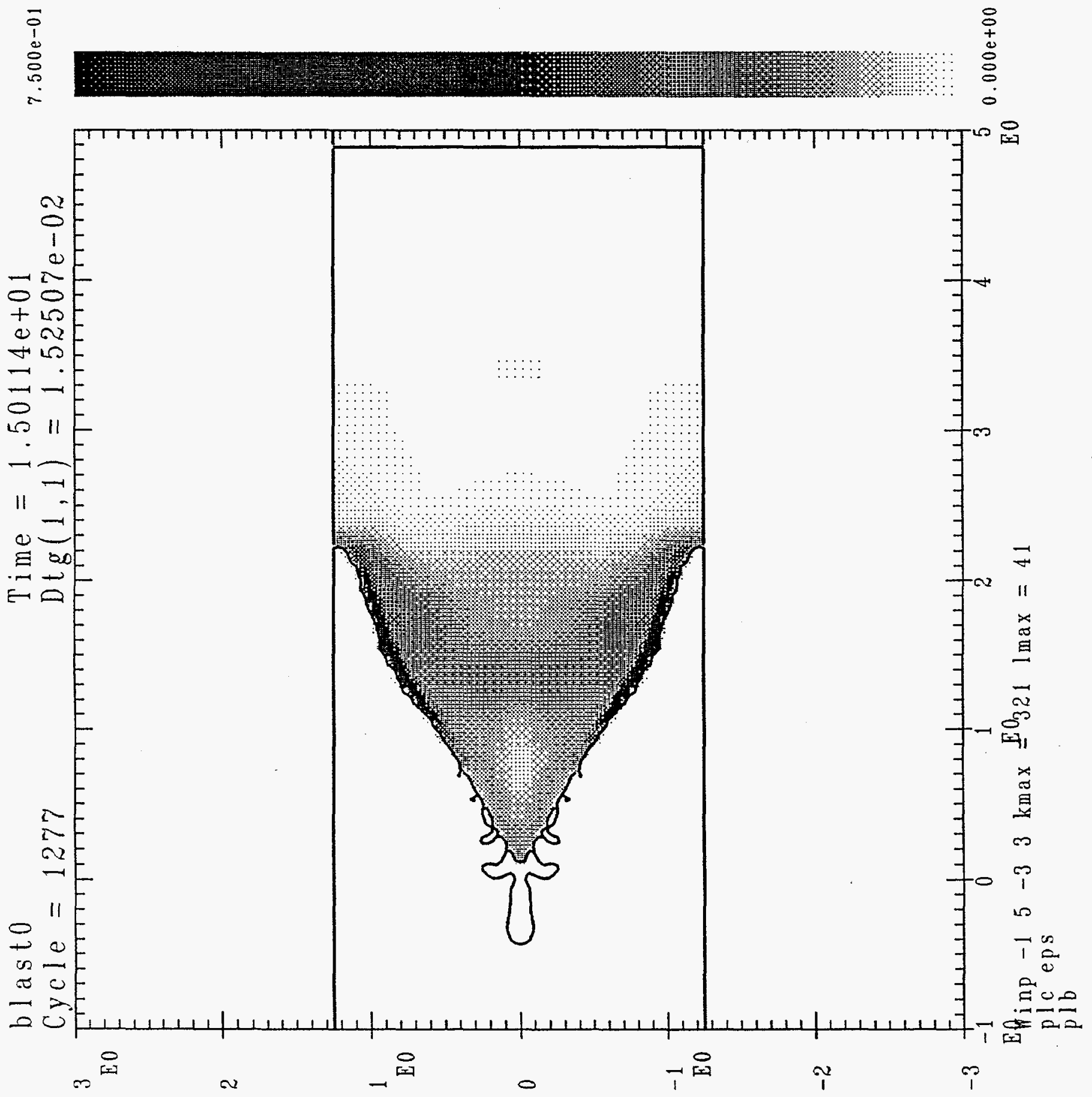